\title{
Parkinsonism as a neuropsychiatric presentation in CNS gnathosomiasis: its prevalence
}

\author{
Parkinsonismo como uma apresentação neuropsiquiátrica da gnatosomiase do sistema \\ nervosa central: sua prevalência
}

Sir, parkinsonism (PD) is an important neuropsychiatric disorder. Kummer and Teixeira noted that "behavioral and psychological symptoms or neuropsychiatric syndromes associated with PD are frequent and may represent a challenge in the management of these patients ${ }^{1}$." The degenerative defect in brain tissue can be seen in the patients with parkinsonism. The exact etiology of parkinsonism is not well understood. However, some brain pathologies can result in parkinsonism. Of several problems, the CNS infection that can lead to parkinsonism is very interesting ${ }^{2}$. The CNS parasitosis is a common tropical neurological infectious disease that can induce parkinsonism. Here, the authors discussed on the prevalence of parkinsonism as a neuropsychiatric presentation in CNS gnathosomiasis. Based on the study on 126 Thai cases with CNS gantosomiasis ${ }^{3}$, it can be seen that there is 1 case presenting with parkinsonism giving the prevalence rate equal to $0.79 \%$. Indeed, gnathostomiasis is a nematode tissue infection ${ }^{4}$. The neurological involvement of this disease can be seen and can induce some uncommon neurological manifestations ${ }^{4}$. Based on the present data, it can be seen that there should be many cases of parkinsonism that has the underlying gnathostomiasis. Since gnathostomiasis can be effectively treated by antiparasitic drug, the investigation for this parasitosis in any patients presenting with parkinsonism in the endemic area is recommended.

Hai Err', Viroj Wiwanitkit ${ }^{2}$

\section{References}

1. Kummer A, Teixeira AL. Neuropsychiatry of Parkinson's disease. Ara Neuropsiquiatr 2009;67:930-939.

2. Olanow CW, McNaught K. Parkinson's disease, proteins, and prions: milestones. Mov Disord 2011;26:1056-1071.
Wiwanitkit V. Update in Infectious Diseases. New York: Bentham Science, 2009.

4. Hughes AJ, Biggs BA. Parasitic worms of the central nervous system: an Australian perspective. Intern Med J 2002;32:541-553. 